\title{
EXTENSÃO UNIVERSITÁRIA E POLÍTICAS PÚBLICAS
}

Lucas Batista Pereira ${ }^{1}$

\section{RESUMO}

Este artigo tem por objetivo discutir a relação entre extensão universitária e políticas públicas. Tendo como referência o documento elaborado pelo Fórum dos Pró-Reitores de Extensão das Universidades Públicas Brasileiras, discute a concepção de extensão utilizada nas universidades. $\mathrm{Na}$ condição de reflexão sobre as políticas públicas, foi analisado o Programa Josué de Castro, formulado pelo Ministério da Educação (MEC), que tem como objetivo favorecer a formação acadêmica pela extensão dos estudantes universitários, além de buscar a parceria das instituições públicas de ensino superior na erradicação da fome e da miséria no país. Nessa mesma linha de concepção, o MEC, em parceria com diversos órgãos federais, lançou o edital de convocação destinado às instituições públicas para apresentação de propostas extensivas, por meio do Programa de Extensão Universitária (PROEXT). A participação das universidades em programas públicos é de total relevância, não somente na implementação destas, como também na contribuição do aumento de uma consciência crítica da população e do fortalecimento de seu poder de reivindicação. $O$ incentivo que pode ser dado pelas universidades proporciona uma maior interação destas com as camadas mais pobres, esse é o caminho mais adequado para contribuir na erradicação dos problemas mais graves e complexos da sociedade.

Palavras-chave: Extensão Universitária. Políticas Públicas.

${ }^{1}$ Professor Doutor do Departamento de Geografia da Universidade Estadual do Sudoeste da Bahia (UESB). Ex-Presidente do Fórum de Pró-Reitores de Extensão das Universidades Públicas Brasileiras e da União Iberoamericana de Extensão Universitária. E-mail: lucabatistap@ig.com.br

\begin{tabular}{l|l|l|l|l}
\hline Revista Extensão \& Cidadania & Vitória da Conquista & v. 1, n. 1 & p. 91-104 & jan./jun. 2013 \\
\hline
\end{tabular}




\begin{abstract}
This article aims to discuss the relationship between university extension and public policy with reference to the document prepared by the Forum of Prorectors of Extension of Brazilian Public Universities that discusses the concept of extension used in universities. As a reflection on public policy program was analyzed Josué de Castro, made by the ministry of Education (MEC) in order to promote academic, by extension, of university students and to seek the partnership of the Public Institutions of Higher Education in eradicating hunger and poverty in the country. By the same design, the MEC in partnership with several federal agencies, launched the Call for extension proposals, through programs and projects, public institutions, through the University Extension Program (PROEXT). The Role of Universities in public programs is discussed considering the importance, not only in their implementation as well as providing a positive contribution in raising awareness of critical population and strengthening their power to make demands. The incentive can be given by universities motivating greater interaction with the poorest sections of society is the most appropriate way to face the serious and complex problems of the countries.
\end{abstract}

Keywords: University Extension. Public Policy. Society

\title{
1 Extensão Universitária
}

A discussão sobre o conceito de extensão universitária é um debate bastante amadurecido no âmbito acadêmico, no entanto nem sempre é possível perceber, em cada instituição de ensino superior, qual concepção serve como base teórica de referência para as ações extensivas. Portanto, ainda permanece a discussão de como cada instituição, por meio da diversidade de ações extensivas, concebe na prática a extensão universitária.

Em 1995, o Fórum de Extensão dos Pró-Reitores das Universidades Públicas Brasileiras elaborou um relatório que identifica ou precisamente define indicadores que permitem compreender como se materializa a concepção de extensão nas respectivas instituições públicas. O levantamento foi feito com o auxílio de um questionário formalizado dentro dos instrumentos legais de cada instituição de ensino superior pública, o qual permitiu, em primeiro plano, a 
compreensão de que a função básica da extensão se estabelece na articulação entre a sociedade e a universidade e que por meio dessa articulação a extensão leva a universidade ao cumprimento de sua missão social (BRASIL, 2007).

Apesar de saber que o incentivo à extensão deva ser primordial, as universidades não definem como essa extensão será promovida. $\mathrm{O}$ cumprimento dessa função e missão só será possível na articulação entre o ensino e a pesquisa, em que se estabelece uma alimentação/ retroalimentação entre os pilares de qualquer universidade, que tenha como diretriz a indissociabilidade entre extensão, ensino e pesquisa na organização das políticas institucionais.

Se, por um lado, a universidade compreende a função primordial da ação extensiva na articulação do estudante com a sociedade, por outro, depara-se com aspectos teóricos e políticos de como se deve por em prática essa articulação, com base nas seguintes questões: a articulação deve atender a todos os segmentos sociais da sociedade? Ao setor empresarial (urbano ou rural) ou aos trabalhadores (urbano ou rural)? Deve existir uma articulação maior com os movimentos sociais ou com os "movimentos" governamentais? Nessa relação de articulação, está se falando em atividades docentes e/ou discentes, e/ ou técnico-administrativo ou está se falando em uma "prestação de serviços" da instituição? Essa relação é importante para a realimentação com o ensino e pesquisa ou é uma mera captação de recursos por parte da universidade? Como se vê, a questão toma uma maior complexidade e é merecedora de maior discussão e aprofundamento.

\section{Políticas Públicas}

Para debater as questões levantadas anteriormente, vamos relacionar a extensão universitária com as políticas públicas. Citaremos dois documentos elaborados pelo governo federal, por meio de diversos órgãos governamentais. 


\subsection{O Programa Josué de Castro}

O Programa Josué de Castro, proposto neste ano pelo Ministério da Educação (MEC), por meio de sua Secretaria de Ensino Superior, foi concebido com o

[...] intuito de favorecer a formação acadêmica, pela extensão, dos estudantes universitários e de buscar a parceria das Instituições Públicas de Ensino Superior na erradicação da fome e da miséria no país, pauta essa capaz de integrar as forças do Estado e da Sociedade Civil e que não pode prescindir da contribuição da Universidade Brasileira (BRASIL, 2011b, p. 5).

A concepção do Programa está vinculada a projetos e às ações governamentais de diversos órgãos institucionais, pois está relacionada ao setor público. No entanto, incorpora ou está alinhada ao Plano Nacional de Extensão Universitária elaborado pelo Fórum dos PróReitores de Extensão das Universidades Públicas Brasileiras, que tem como objetivo ser um mecanismo de motivação e também oferecer meios necessários para a estruturação da área de extensão das universidades públicas. O Plano Nacional de Extensão Universitária considera a extensão fator essencial na formação dos estudantes das universidades brasileiras. Trata-se de um programa com forte preocupação acadêmica e com a geração de conhecimentos construídos junto ao saber popular que proporciona o desenvolvimento do senso de cidadania e justiça social. Em suma, é uma política de formação dos profissionais do futuro, que devem conhecer e se comprometer com a realidade nacional (FÓRUM DOS PRÓ-REITORES, 2001).

A intenção do MEC, conforme descrito no documento, ao procurar as universidades, demonstra o significado e a importância da relação entre as instituições e a sociedade. Estão nelas as possibilidades de uma intervenção direta na perspectiva de buscar soluções dos problemas existentes em nosso país, já que é do conhecimento destas, por meio de processos investigativos, o diagnóstico que é fundamental no processo de intervenção. 
As linhas de ações constantes no Programa Josué de Castro expressam o que foi dito, o que concerne aos aspectos da realidade social e estão relacionadas a:

- Erradicação da fome e da miséria, nos seguintes temas: segurança alimentar e nutricional, produção de alimentos, inovação tecnológica;

- Educação: alfabetização, leitura e escrita; formação de professores, crianças, jovens e adultos; educação profissional; empreendedorismo;

- Saúde: grupos sociais vulneráveis, infância e adolescência, saúde e proteção no trabalho. Saúde humana, saúde animal, saúde da família, endemias e epidemias;

- Cultura: música, teatro, dança; organizações da sociedade civil e movimentos sociais e populares;

- Trabalho e geração de renda: desenvolvimento de produtos, emprego e renda, desenvolvimento regional rural e urbano; desenvolvimento da questão agrária, desenvolvimento tecnológico; - Gestão do trabalho, gestão informacional, gestão institucional, gestão pública;

- Inclusão digital: mídia/artes, mídias, tecnologia da informação; Esporte: esporte e lazer;

- Vulnerabilidade por questões ambientais: enchentes, desmoronamentos, soterramentos, incêndios, secas, lixo, acesso à água, saneamento e urbanização;

- Vulnerabilidades sociais: Uso de drogas e dependência química; segurança pública e defesa social, desenvolvimento humano, violência urbana, chacinas, atingidos por barragens, atingidos por remoção;

- Direitos humanos: direitos individuais e coletivos.

Como se vê, existe uma gama de questões que também se interligam com os debates e às ações dentro das universidades. 


\subsection{Ações direcionadas do Programa}

Conforme descrito no Programa Josué de Castro, existe uma preocupação em estabelecer algumas relações com o fortalecimento da extensão nas instituições de ensino superiores, numa perspectiva de constituir deliberações mais contínuas e estruturadas que priorizem as ações extensivas nas universidades. Com isso, deve-se assegurar que $100 \%$ da extensão desenvolvida no Programa valorize sua dimensão pedagógica e de construção do conhecimento no âmbito da sua instituição. Outras ações direcionadas podem ser destacadas nessa perspectiva:

- Incorporar nos projetos pedagógicos (de todos os cursos de graduação) o desenvolvimento, pela extensão, dos seguintes aspectos formativos: conhecimento da realidade nacional, pensamento crítico, cidadania ativa, trabalho em equipe, senso de solidariedade e justiça social.

- Promover a revisão dos projetos pedagógicos dos cursos de graduação à luz das diretrizes curriculares da área, a fim de favorecer a inserção da extensão como estratégia formativa.

- Incorporar ao menos 10\% do total de horas curriculares de formação acadêmica em programas e projetos de extensão fora dos espaços de sala de aula.

- Reconhecer horas de integralização curricular pela atuação em projetos e programas de extensão, com o Programa Josué de Castro.

- Promover o exercício da indissociabilidade entre ensino, pesquisa e extensão de forma a assegurar a dimensão acadêmica da extensão na formação dos estudantes.

Outro aspecto relevante é da necessidade das instituições de estabelecer maiores parcerias com outras instituições públicas, privadas e não governamentais, com o intuito de promover um diálogo com a realidade social mais próxima, por meio de consórcios com os programas institucionais desenvolvidos pelos governos locais, nos municípios do entorno das instituições. 
Sem dúvida, esse chamamento é de suma importância, pois estimula o conhecimento da realidade local por meio da extensão. Outro aspecto importante é a promoção do atendimento às demandas mais reprimidas da população que objetiva a formação de mão de obra qualificada para o trabalho, a reorientação profissional e, principalmente, a capacitação de gestores públicos.

Ao promover ações como essas, as instituições podem estabelecer a relação com a pesquisa ao diagnosticar a realidade local, os problemas existentes e as perspectivas de soluções.

Observamos então a relevância da extensão, pois propicia uma formação mais completa dos estudantes. Esse envolvimento dos alunos dos cursos de graduação com âmbitos que ultrapassam a estrutura curricular, além de favorecer o conhecimento da realidade regional e nacional, como foi destacado anteriormente, possibilita maior autonomia intelectual, pensamento crítico, rompimento com o individualismo e estimula, também, a busca de solidariedade e justiça social. Assim sendo, os alunos praticarão uma cidadania ativa consigo e com as demais pessoas.

Os parceiros, ao desenvolverem práticas extensivas com as instituições universitárias, principalmente os governos locais, poderão cumprir com sua missão essencial de promover a melhoria da qualidade de vida da população. Por meio de políticas públicas estruturadas e consolidadas, os parceiros poderão: capacitar cada vez mais seus quadros de servidores, estabelecer relações com futuros profissionais nas áreas diversas do conhecimento e sanar, assim, um dos problemas ainda existentes em grande parte dos municípios de pequeno porte do nosso país, a falta de profissionais formados, qualificados, conhecedores da realidade na qual estão se inserindo.

A visão aqui exposta reflete a experiência que vivenciamos com o trabalho extensivo durante vários anos dentro das universidades. Contudo não é um pensamento utópico, é uma necessidade posta às instituições universitárias. A experiência de melhor conhecer a realidade, principalmente as mais carentes, e ser um agente de transformação dessa 
realidade, favorece a autoestima profissional e desenvolve habilidades só possíveis de serem assimiladas em situações novas e incertas, que criam o sentido de liderança e solidariedade nos indivíduos participantes. Desse modo, eles superarão com mais facilidade as inseguranças ao se depararem com as primeiras experiências profissionais.

\section{Programa de Extensão Universitária (PROEXT 2011)}

Nesta mesma linha de concepção, o Ministério da Educação, em parceria com diversos órgãos federais, lançou o edital de convocação para apresentação de propostas extensivas, por meio de programas e projetos a serem realizados pelas instituições públicas, com o apoio do Programa de Extensão Universitária (PROEXT).

O objetivo do Programa (PROEXT) é fornecer condições de fomento para o desenvolvimento de atividades extensivas nas instituições superiores públicas e fortalecer as políticas públicas da área social do governo federal. Contudo, os programas e projetos apresentados pelas instituições devem atuar sobre questões sociais e, além disso, obedecer às diretrizes de natureza acadêmica e de relação com a sociedade.

No plano interno das instituições, o edital estabelece a concepção de valorização, pois estas já possuem uma política extensiva, e destaca:

- Todos os programas e projetos concorrentes devem cumprir os procedimentos acadêmicos da Instituição de Educação Superior, demonstrado que as atividades de extensão possuem vinculação com os componentes curriculares dos cursos de graduação envolvidos. As propostas devem ser aprovadas nas instâncias competentes, cabendo às pró-reitorias de extensão a seleção interna das propostas, e só posteriormente enviadas ao MEC (BRASIL, 2011a).

Tal fundamento, se discutido democraticamente nas instituições, podem, por um lado, proporcionar o fortalecimento dos programas e projetos de ação continuada e, por outro, estabelecer uma relação maior com o ensino de graduação. 
Ainda nesse raciocínio, muitos programas e projetos das instituições, principalmente das públicas, possuem parcerias com outras instituições públicas, privadas ou instituições não governamentais, pois é recomendável o fortalecimento das ações para a ampliação de recursos, a capacitação de pessoal e para uma maior articulação da universidade com a sociedade.

Outro fundamento relevante estabelecido no edital vincula-se à participação dos discentes nas atividades extensivas, ao estabelecer que:

- As atividades previstas de extensão deverão estar articuladas ao processo de formação acadêmica dos estudantes em seus respectivos cursos, mediante articulação dessas com os componentes curriculares, disciplinas;

- É recomendável a previsão das atividades de extensão nos projetos pedagógicos de cursos para que atividades de extensão universitária realizadas pelos alunos sejam computadas na integralização curricular de seus cursos;

- Somente alunos da instituição proponente poderão ser bolsistas.

Ao citar esses dois fundamentos constantes no edital, podemos perceber a existência de uma consonância com as diretrizes estabelecidas pelo Programa Nacional de Extensão, elaborado pelo Fórum Nacional, e com as temáticas principais para o desenvolvimento dos programas e projetos, como: educação, tecnologia para o desenvolvimento social, cultura e arte, promoção da saúde, desenvolvimento urbano e rural, redução das desigualdades sociais e combate à pobreza extrema, geração de trabalho e renda por meio de apoio de programas solidários, preservação do patrimonial cultural brasileiro, direitos humanos, promoção da igualdade social e relações de gêneros.

Ao destacar esses exemplos de ações governamentais, procuramos chamar a atenção da necessidade das instituições universitárias, principalmente as públicas, de criarem uma maior relação com essas políticas, com maior envolvimento no desenvolvimento extensivo, como no Programa Josué de Castro e no edital do MEC. 
Nesse sentido, torna-se relevante uma discussão no âmbito político sobre a participação das universidades nas políticas públicas governamentais, por ser esse um tema que ainda permeia nas discussões internas das instituições.

\section{Participação das Universidades nas Políticas Públicas}

O centro desta questão nos remete ao papel do Estado nas sociedades atuais, especificamente o Estado brasileiro, tratado neste trabalho. A fundamentação para tais questões é encontrada na forma de como o sistema capitalista se desenvolve. Quando falamos em sistema capitalista também falamos em Estado, na condição de categoria sociológica, já que um está imbricado ao outro. Por que tal fato acontece? Porque desde o surgimento da estrutura capitalista em todo o mundo o setor público nunca deixou de existir. Numa simplificação de conceitos, o Estado é a manifestação da esfera pública.

No atual contexto do Estado brasileiro, é necessário uma releitura do seu papel na perspectiva de torná-lo promotor das políticas públicas que beneficiem a extensão universitária.

Consideramos, portanto, importante uma reflexão sobre o padrão de intervenção do Estado na sociedade brasileira. Concordamos que em nenhum momento da história, desde a sua criação, o Estado deixou de gerar as condições necessárias para a acumulação de capital e para a manutenção da ordem estabelecida, numa perspectiva de atender uma classe mais privilegiada.

Expondo sobre a crise econômica mundial que abalou o mundo em 2008, numa participação no Fórum Social Mundial de 2009, o sociólogo português Boaventura de Souza Santos propõe "a reinvenção do Estado" como resposta às crises. $\mathrm{Na}$ ocasião ele declarou que "o impensável ocorreu: o Estado deixou de ser o problema para voltar a ser a solução" (FÓRUM SOCIAL MUNDIAL, 2009, p. 2).

Parafraseando o raciocínio de Boaventura, entendemos que o Estado, dentro do contexto atual do governo federal, vem procurando alternativas ao receituário exclusivo neoliberal, com a compreensão 
de que ele deve assumir o planejamento de certas funções enquanto agente e, paralelamente, promover a participação social e, com isso, favorecer a democratização da sociedade como um todo. Partindo dessa premissa, é preciso buscar o compartilhamento dos setores sociais, privado e público, para governar, administrar, dirigir e orientar o mecanismo de mercado e atingir o interesse nacional.

É nesse âmbito que propomos a participação das universidades públicas nas ações governamentais. Com isso, fortaleceremos, a cada dia, a democracia na sociedade civil brasileira, que demonstra um maior nível de organização e liberdade para facilitar as decisões e diminuir a dependência de um bom ou mau funcionamento do Estado.

Entendemos aqui o papel primordial do estado brasileiro em diversos segmentos da sociedade e principalmente no que tange às melhorias voltadas para aqueles cidadãos mais excluídos na sociedade contemporânea. No entanto, seria mais prudente afirmar que nem todos os Programas e Ações públicas encontram os canais de participação para influir na resposta que esperam os grupos que as formulam. É nesse aspecto que a participação das universidades se faz primordial, pois ao se envolverem nas ações governamentais objetivam influir em uma decisão que se encontra fora do alcance de muitos cidadãos.

Portanto, a participação das universidades em programas públicos assume significado especial devido ao desenvolvimento geral com a não marginalização do povo nos assuntos que interessam a todos, mas são na realidade, decididos por poucos. Estas são contribuições positivas que a Universidade pode oferecer: facilitar o aumento da consciência crítica da população e fortalecer seu poder de reivindicação. $\mathrm{O}$ incentivo dado pelas universidades motiva uma maior interação com as camadas mais pobres da sociedade. Observamos então que a descentralização das políticas públicas é o caminho mais adequado para o enfrentamento dos graves e complexos problemas dos países.

A questão, portanto, pode ser colocada da seguinte forma: por intermédio de ações diretas nas políticas públicas é possível reativar 
o pensamento social crítico e até mesmo a práxis política das classes subalternas? Conforme destaca Gramsci (2004) o povo sente, mas nem sempre compreende e sabe; o intelectual sabe, mas nem sempre compreende e muito menos sente.

Consideramos aqui o Estado como solução, pois ele deve assumir o planejamento de certas funções na condição de agente e, paralelamente, promover a participação social, e assim, favorecer maior acesso e controle social por parte da sociedade. Contudo, é preciso buscar o compartilhamento dos setores sociais, privado e público, para governar, administrar, dirigir e orientar as ações das políticas públicas. As universidades, fora desse contexto, podem sofrer as consequências de um retrocesso na sua função social.

Nesse sentido, entende-se necessária a reflexão sobre as políticas públicas, como princípio para o desenvolvimento do país. $\mathrm{Na}$ perspectiva de compreendê-lo como uma mudança social positiva, devese considerar as expectativas dos grupos sociais concretos, com seus valores culturais próprios e suas particularidades histórico-geográficas. Desenvolvimento é mudança, isto é, mudança para melhor.

A universidade, ao colaborar na execução das políticas públicas, procura contribuir com uma melhoria da qualidade de vida e um aumento da justiça social em nosso país. A mudança social positiva precisa contemplar, primordialmente, os menos favorecidos, muitos deles distanciados das ações da extensão universitária.

\section{Considerações Finais}

Se a comunidade acadêmica priorizar as dificuldades para o desenvolvimento das atividades extensivas, inclusive o debate sobre as limitações de recursos financeiros, a discussão já se enceraria por aqui, visto que esse aspecto é uma realidade na maioria das instituições públicas e privadas.

Poderíamos dizer, sem dúvida, ser este, ou seja, os parcos recursos que hoje são direcionados à extensão universitária, um impeditivo, mas não o suficiente para o não desenvolvimento dessa 
prática. Nesse contexto, surge um questionamento: como, por intermédio da participação na implementação de políticas públicas, a extensão universitária pode ser melhor posta em prática?

A estrutura curricular dos cursos de graduação se insere como de fundamental importância nesse aspecto. Se não existir uma relação do teórico com o prático, e, neste caso, a extensão como atividade prática, a formação fica prejudicada, isso porque compreendemos que não se concebe a teoria desvinculada da prática, da explicação da realidade, ou seja, "o que existe" e o "por que existe" estão interligados.

Nesse sentido, os nossos discentes vão perceber e refletir sobre a verdadeira relação existente entre a universidade e a sociedade. Ficar "dentro" da universidade, aprendendo conteúdos sem correlacionar com o que acontece lá "fora", é possuir uma visão estereotipada do processo de aprendizagem.

Ao participar de um programa que visa erradicar o analfabetismo em nosso país, o discente passará a compreender melhor essa problemática, por que ela existe, em que contexto ela se insere e como ela se concretiza, identificando as principais características que a constituem. Os alunos também podem entender melhor o desenvolvimento das políticas sociais básicas, no caso a educacional, a sua forma de organização institucional e os resultados no que concerne à melhoria da qualidade de vida da população, que, sem dúvida, deve ser o objetivo maior da Universidade.

Por fim, os seguintes questionamentos precisam vir à tona: por que é importante identificar as dimensões práticas de determinados conceitos, ou determinadas categorias de análise, discutidas em sala de aula? Por que é necessário o envolvimento do estudante em atividades extensivas? Em suma, a resposta direta está em identificar e sentir os fatos na realidade.

É notório o avanço da prática extensiva nas instituições públicas de ensino superior, fruto da busca permanente daqueles que a praticam e reconhecem a sua relevância. Foi um grande período de acúmulo de conhecimento, advindo de uma prática coletiva de pensar e refletir sobre o significado da ação extensiva. Em decorrência desse 
acúmulo é que se tem hoje possibilidades de entendimento, por parte dos governos, de que as instituições universitárias são parceiras, mas que têm a sua forma de ser e de compreender os problemas existentes e propor soluções para estes.

Esperamos ter atingido o nosso objetivo de levantar algumas questões para uma reflexão sobre a extensão universitária, num contexto o qual todos almejam melhorias generalizadas das condições de vida da população brasileira que é estabelecida por meio de uma articulação consciente e permanente na elaboração e concretização das políticas públicas, ação imprescindível para a consolidação de uma sociedade democrática e participativa.

\section{Referências}

BRASIL. Ministério da Educação. Secretaria de Educação Superior. Fórum de Pró-Reitores de Extensão das Universidades Públicas Brasileiras. Institucionalização da Extensão nas Universidades Públicas Brasileiras: estudo comparativo 1993/2004. Belo Horizonte: COOPMED, 2007.

- Ministério da Educação. Programa de Extensão Universitária

- PROEXT 2011. Brasília, 2011. Disponível em: <www.mec.org.br>. Acesso em: 23 jul. 2011a.

. Ministério da Educação. Fórum Nacional de Pró-Reitores de Extensão (FORPROEX). Programa Josué de Castro. Brasília: MEC, 2011. Disponível em: <http://www.mec.org.br>. Acesso em: 15 ago. 2011b.

FÓRUM DE PRÓ-REITORES DE EXTENSÃO DAS UNIVERSIDADES PÚBLICAS BRASILEIRAS. Plano Nacional de Extensão Universitária. Belo Horizonte: UFMG, 2001. Disponível em: <http://www.renex.org.br>. Acesso em: 09 set. 2011.

FÓRUM SOCIAL MUNDIAL. Boaventura de Sousa Santos defende "a reinvenção do Estado" como resposta às crises. Porto Alegre, 2009. Disponível em: $\quad<$ http://ultimahora.publico.clix.pt/noticia.aspx?id=1358358>. Acesso em: 10 out. 2009.

GRAMSCI, Antonio. A questão meridional. In: Id. Escritos Politicos. Rio de Janeiro: Civilização Brasileira. [1926] (2004). 